\title{
A Senior Design Project: Heating and Cooling System for Car's Interior
}

\author{
Mr. Everardo Frias Rios \\ Dr. Ahmed S. Khan, DeVry University, DuPage
}

Everardo Frias Rios, is pursuing a B.S degree in Electronics Engineering Technology (EET) at DeVry University, Addison, Illinois.

Christopher Aldridge is pursuing a B.S degree in Electronics Engineering Technology (EET) at DeVry University, Addison, Illinois.

Victor Ramirez is pursuing a B.S degree in Electronics Engineering Technology (EET) at DeVry University, Addison, Illinois.

Dr. Darryl Padgett is the Associate Dean of The College of Engineering \& Information Sciences, DeVry University, Addison, Illinois.

Dr. Ahmed S. Khan is a senior professor in the College of Engineering \& Information Sciences, DeVry University, Addison, Illinois. Dr. Khan served as the adviser to the project presented in this paper.

\section{Dr. Darryl Vince Padgett, DeVry University, Addison}

Dr. Padgett is the Associate Dean for the College of Engineering and Information Systems and the Associate Dean for the College of Media Arts and Technology at DeVry University. He is responsible for managing faculty development and ensuring that the faculty delivers exceptional educational service to the students and university. His colleges are also responsible for creating the foundation for the students in their field of studies. Dr. Padgett received his undergraduate and master's degree from Tuskegee University and his Ph.D. from The University of Alabama in Electrical Engineering. Dr. Padgett has a diverse background in engineering. His management experience includes directing multiple departments and managing a startup engineering team in Atlanta, Georgia. He has provided technical direction and guidance, as well as hands-on project management, for product design, development, testability and product sustainability. Dr. Padgett has worked as an individual contributor and senior engineering manager for companies such as AT\&T, Westinghouse Electric, IBM, Texas Instruments, Lucent/Agere Systems, Department of Navy and Air Force as well as Northrop Grumman. Dr. Padgett was an assistant professor at Tuskegee University teaching analog and digital IC Design Courses. He has conducted external research for the Department of Defense and defense companies. His external research contracts grew from $\$ 6 \mathrm{~K}$ to $\$ 250 \mathrm{~K}$ per year and funded many undergraduate and graduate students. Dr. Padgett provided university service and worked on various committees. Dr. Padgett spends a considerable amount of time working on Science, Technology, Engineering and Mathematics (STEM) initiatives. He strongly believes in reaching back introducing STEM into high risk elementary schools. He participates in science nights, science competitions and science demonstrations that expose students to the STEM areas. There are many people that helped Dr. Padgett reach his career and personal goals in life. Dr. Padgett feels strongly about giving back to the community and trying to make a difference in the lives of others. He is paying it back and paying it forward. Dr. Padgett restores antique automobiles and loves to tinker on things in his spare time. Dr. Padgett is also a long distance motorcycle rider. He commutes approximately 140 miles per day to work on his bike. He has traveled to as far as Ohio, Louisiana, Florida and Texas and it doesn't bother him to travel $1600-1800$ miles over three day period. He is currently planning a trip on his bike to Niagara Falls and New York via Canada and next summer to Alaska or California. Dr. Padgett enjoys exploring and seeing the country on two wheels. Being on a motorcycle allows you to see things that you would never notice when you are traveling in a car. Life-long learning on a motorcycle is a wonderful way to learn about America's history and culture. 


\title{
A Senior Design Project: Heating and Cooling System for Car's Interior
}

\begin{abstract}
This paper describes the design and implementation of a senior project involving a car heating and cooling system. During the summer and winter times, for cars parked outside, the interior temperature can become very high or very low causing discomfort for the driver and passengers. Therefore a device is needed to keep the vehicle interior at comfortable temperatures while standing on the parking lot or on the driveway.

The goal of this project was to build a light weight compact car heater and cooler. The car heating and cooling system allows car users to maintain a reasonable temperature while sitting at home or in a parking lot. The designed system can fit in a back window. The system runs using a $12 \mathrm{~V}$ DC power source powered through a solar panel that is mounted on the back window of the vehicle. This location was chosen because the exposure to light is greater in the rear and allows the solar panel to recharge faster and more efficiently. All components used in this system are rated $12 \mathrm{VDC}$, with the exception of the microcontroller; an additional $5 \mathrm{~V}$ DC regulator is used to power the Arduino microcontroller. Using a thermistor, the microcontroller tracks the temperature inside a vehicle. When a high temperature (i.e. temp $>70^{\circ} \mathrm{F}$ ) condition is detected by the thermistor, the microcontroller 1 enable s a power relay to apply power to both the fan and the cooling element, based on a peltier and heat sink. This process continues until the temperature is within the specified range (i.e. $66^{\circ} \mathrm{F} \sim 70^{\circ} \mathrm{F}$ ) or until user disables the system.

In the same manner, when a low temperature (i.e. temp $<66^{\circ} \mathrm{F}$ ) is detected by the microcontroller through the thermistor, a power relay is enabled to apply power to both the fan and the heating element, also based on a peltier and heat sink. This process continues until the temperature is within the specified range (i.e. $66^{\circ} \mathrm{F} \sim 70^{\circ} \mathrm{F}$ ) or until user disables the system. As an additional feature, an air freshener pump is also included in the system that can be activated at 30 minute intervals and will continue until user disables the system. All features and temperature measurements are tracked and displayed on the LCD which is connected to the Arduino microcontroller. The paper covers the details of the design of hardware and software components of the system.
\end{abstract}

\section{DeVry University's Senior Project Capstone Course Sequence}

DeVry University's Electronics Engineering Technology program senior project is a four session course sequence in which students synthesize knowledge and skills learned in the previous courses. In the first course (ECET-390 Product Development), students research, plan and develop a project proposal. In the next three courses (ECET-492/493/494), Senior Project Laboratory) students implement the project plan by building and testing a prototype. A typical project involves a solution to a software/hardware based engineering problem. The process of 
developing and implementing a solution to the problem offers a learning opportunity for students to gain new insights and competencies as a result of "constructivist" and "deep learning" teaching/learning approaches.

\section{Project Background}

During the summer and winter seasons, for cars parked outside the cabin temperature can become be too high or too low thus making it difficult for drivers to sit comfortably in the cars to operate them. This paper presents a solution to this problem. The designed project keeps the interior of a car at a comfortable temperature while the car is parked in parking lot or on the driveway.

\section{What is presently available in the Market?}

Similar devices are available in the market but have following limitations:

- Solar cooler powered fans and battery powered heaters have drawbacks.

- Small and inefficient, can't cool/heat entire car

Do not have temperature sensors

- Devices that use the vehicle's battery are not recommended as the battery can die if the device is left on for a long time.

○ Devices that use batteries are expensive to maintain.

- Fans will only blow around the hot air inside the vehicle.

\section{Project Objective}

The objective of this project is to design and implement an effective and inexpensive system to safely heat up or cool down the interior of a compact car when it is parked in parking lot or on a driveway. The designed system will be compact and easy to install with a self-sufficient power supply from a solar panel.

\section{Project Solution}

The characteristics and advantages of the designed project are as follows::

- $\quad$ Equipment will be able to heat/cool an entire compact size car

- $\quad$ The size of the product will fit on to the back window

- $\quad$ Automatic control 
- $\quad$ Available in different colors

- $\quad$ Option for air freshener

- $\quad$ Small and powerful device

- $\quad$ Affordable for every income level

- $\quad$ Self-sufficient power supply, using the sun's energy as shown in figure 1.

- $\quad$ Environmentally friendly device

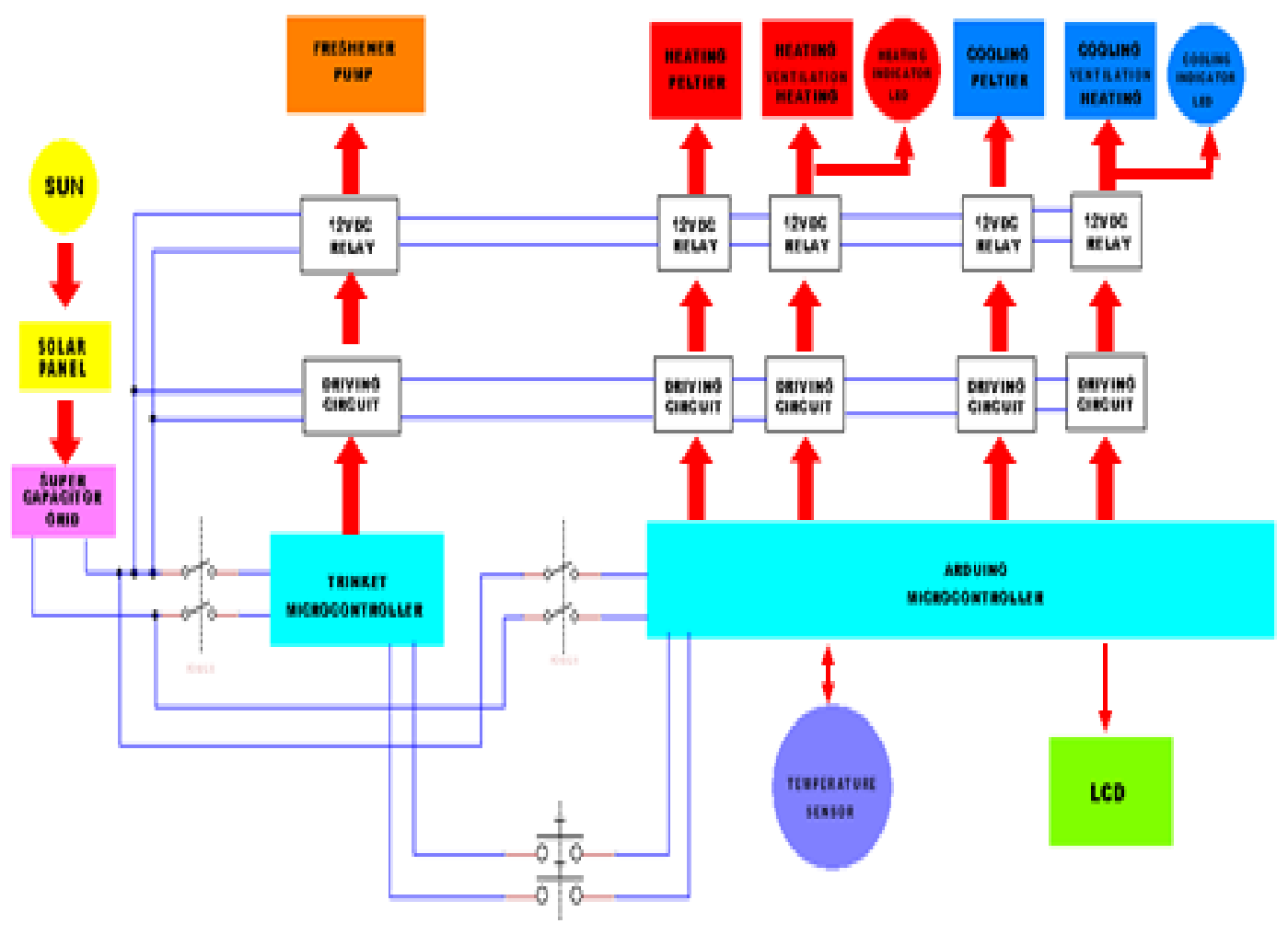

Figure 1: Block Diagram of the Cooling and Heating System

\section{System Description}

Figure 1 illustrates the block diagram of the system. ${ }^{1-11}$ The designed system can maintain a constant temperature inside a vehicle regardless of what the outside temperature is.

The entire system runs using $12 \mathrm{VDC}$ that is provided through a solar panel mounted on the back window of the vehicle. This location was chosen because the exposure to light is greater in the rear and will allow the solar panel to recharge faster and more efficiently. 
All components used in this system are rated 12VDC. Using a thermistor, a microcontroller tracks the temperature inside a vehicle. When a high temperature (temp $>70^{\circ} \mathrm{F}$ ) condition is detected by the thermistor, the microcontroller enables RY1 and RY2 power relays to apply power to both the fan and the cooling element (peltier). This process continues until the temperature reaches within the specified range of $66^{\circ} \mathrm{F} \sim 70^{\circ} \mathrm{F}$ or until user disables the system.

In the same manner, when a low temperature (temp $<66^{\circ} \mathrm{F}$ ) is detected by the microcontroller through the thermistor, RY3 and RY4 power relays are enabled to apply power to both the fan and the heating element (peltier). This process will continue until the temperature is within the specified range of $66^{\circ} \mathrm{F} \sim 70^{\circ} \mathrm{F}$ or until user disables the system.

In order to set desirable the lowest and highest temperature, there are three buttons, select, increase and decrease, as a human interface option. By pressing select button, users can set the highest temperature by using the increasing and decreasing buttons, then the lowest temperature in the same way.

As an optional feature, an air freshener pump could be added to the system that will be activated through RY5 at 1 hour intervals and will continue until user disables the system.

All features and temperature readings are tracked and displayed on the LCD display of the systems (Figure 2).

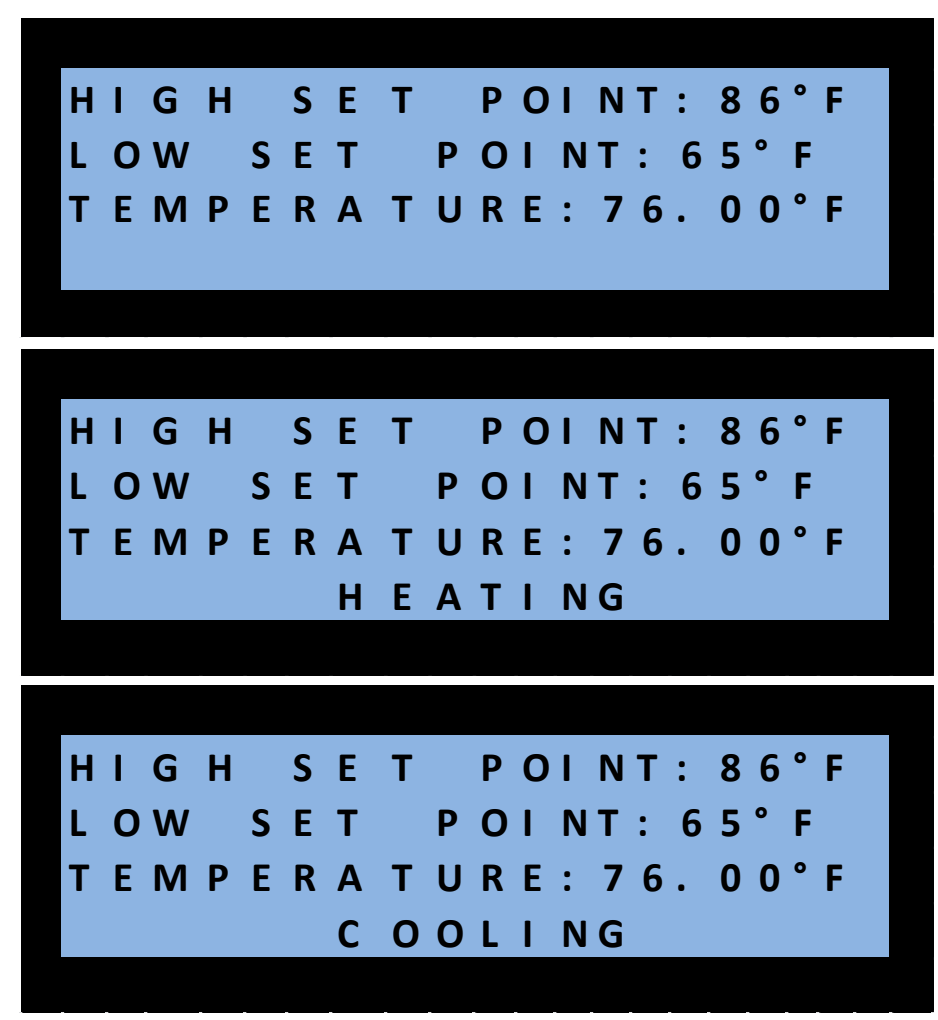

Figure 2: LCD Display of System 
Figure 3 illustrates the details of circuit schematic with two separate cooling and heating elements, each with a peltier, fan and two relays. It also shows the Arduino Leonardo Microcontroller which controls and signals the appropriate elements to turn on turns on, it also sends information to be displayed on the LCD display, based on the measurements it receives from the temperature sensor.

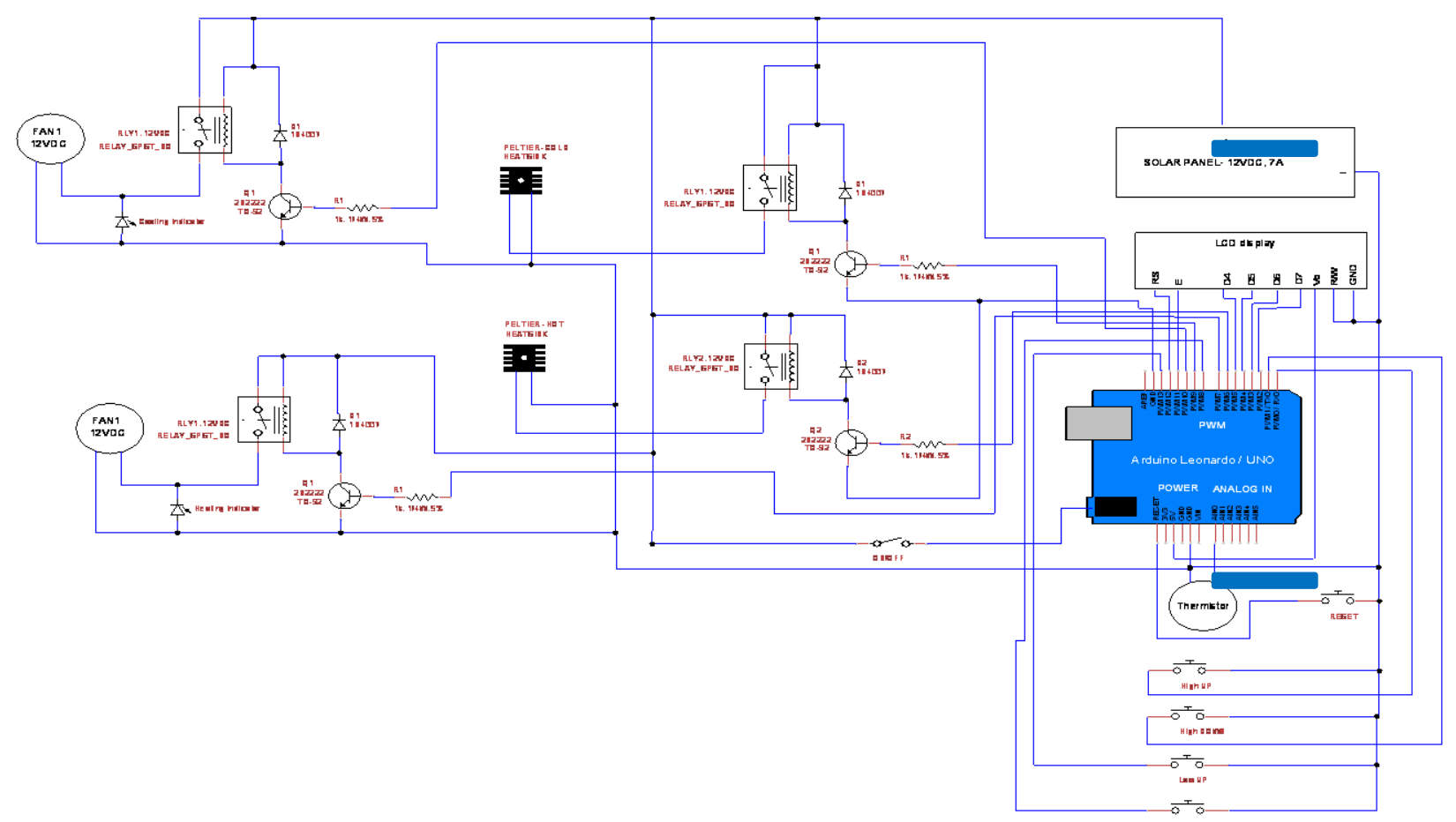

Figure 3. Circuit diagram for cooling and heating elements

\section{Project Schedule}

In order to successfully implement the project in a timely manner various project tasks were assigned to the team members. Table 1 lists all the tasks, time allocations, and persons responsible for completing them. Figure 4 shows the project Gantt chart.

\section{Resources}

Table 2 lists all components ${ }^{1-11}$ and their bill of materials. 
Table 1: Task Allocation

\begin{tabular}{|c|c|c|c|}
\hline Project Task & $\begin{array}{l}\text { Individual (s) } \\
\text { Responsible }\end{array}$ & Time Allocation & Slack Time \\
\hline Project Approval & $C A, E F, V R$ & 3 Weeks & None \\
\hline System Research & $\mathrm{EF}$ & 2 Weeks & 3 Days \\
\hline Component Research & VR & 2 Weeks & 3 Days \\
\hline Component Acquisition & VR & 3 Weeks & 1 Week \\
\hline Software Development & $\mathrm{CA} / \mathrm{EF}$ & 3 Weeks & 1 Week \\
\hline Hardware Design & VR / EF & 2 Weeks & 3 days \\
\hline Software / Hardwarel nterface & $\mathrm{VR} / \mathrm{CA}$ & 3 Weeks & 4 days \\
\hline System Final Design Developmet & $\mathrm{VR} / \mathrm{EF}$ & 2 Weeks & 4 Days \\
\hline System Installation & CA & 2 Weeks & 1 Week \\
\hline System Test & CA & 3 Weeks & None \\
\hline Project Final Report & EF & 1 Week & 3 Days \\
\hline Oral Presentation & CA, EF, VR & 1 Week & None \\
\hline
\end{tabular}

$\mathrm{CA}=$ Chrstopher Aldridge

$\mathrm{EF}=$ Everardo Frias

$\mathrm{VR}=$ Victor Ramirez 


\begin{tabular}{|c|c|c|c|c|c|c|c|c|c|c|c|c|c|c|c|c|c|c|c|c|}
\hline GAnTा & & & August 2013 & & Septem. & er 2013 & & & ober 20 & & & & mber 201 & & & ecember 201 & & & aary 201 & \\
\hline Name & Begin date & End date & $\begin{array}{lll}33 & 34 \\
\end{array}$ & 3536 & 6637 & 30 & 39 & 40 & 41 & 42.43 & 34 & 45 & 46 & 4748 & 84.9 & 5051 & 152 & 12 & 23 & 4 \\
\hline Senior_Project_Proposal & $8 / 12 / 13$ & $8 / 31 / 13$ & & & & & & & & & & & & & & & & & & \\
\hline Component Acquistion & $8 / 26 / 13$ & $8 / 31 / 13$ & & $\square$ & & & & & & & & & & & & & & & & \\
\hline Prototype Development & $9 / 2 / 13$ & $9 / 7 / 13$ & & & $\square$ & & & & & & & & & & & & & & & \\
\hline Software Develooment & $9 / 9 / 13$ & $10 / 25 / 13$ & & & & & & & & & & & & & & & & & & \\
\hline Software / Harware Interface & $9 / 16 / 13$ & $10 / 25 / 13$ & & & & & & & & & & & & & & & & & & \\
\hline Slad Time & $10 / 28 / 13$ & $111 / 2 / 13$ & & & & & & & & & E & ] & & & & & & & & \\
\hline System Final Design Developmet & $11 / 4 / 13$ & $11 / 23 / 13$ & & & & & & & & & & & - & 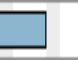 & & & & & & \\
\hline System Instalation & $11 / 25 / 13$ & $12 / 7 / 13$ & & & & & & & & & & & & & & & & & & \\
\hline Slad Time & $12 / 9 / 13$ & $12 / 14 / 13$ & & & & & & & & & & & & & & $\square$ & & & & \\
\hline System Test & $12 / 16 / 13$ & $1 / 4 / 14$ & & & & & & & & & & & & & & & & $\square$ & & \\
\hline Slak Time & $17 / 14$ & $1 / 14 / 14$ & & & & & & & & & & & & & & & & & & \\
\hline Project final Report & $1 / 15 / 14$ & $1 / 22 / 14$ & & & & & & & & & & & & & & & & & & $\square$ \\
\hline & & & 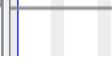 & & & & & & & & & & & & & & & & & \\
\hline
\end{tabular}

Figure 4: Project Gantt Chart

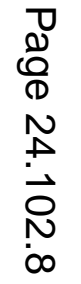


Table 2: Cooling Heating system Bill-of-Materials

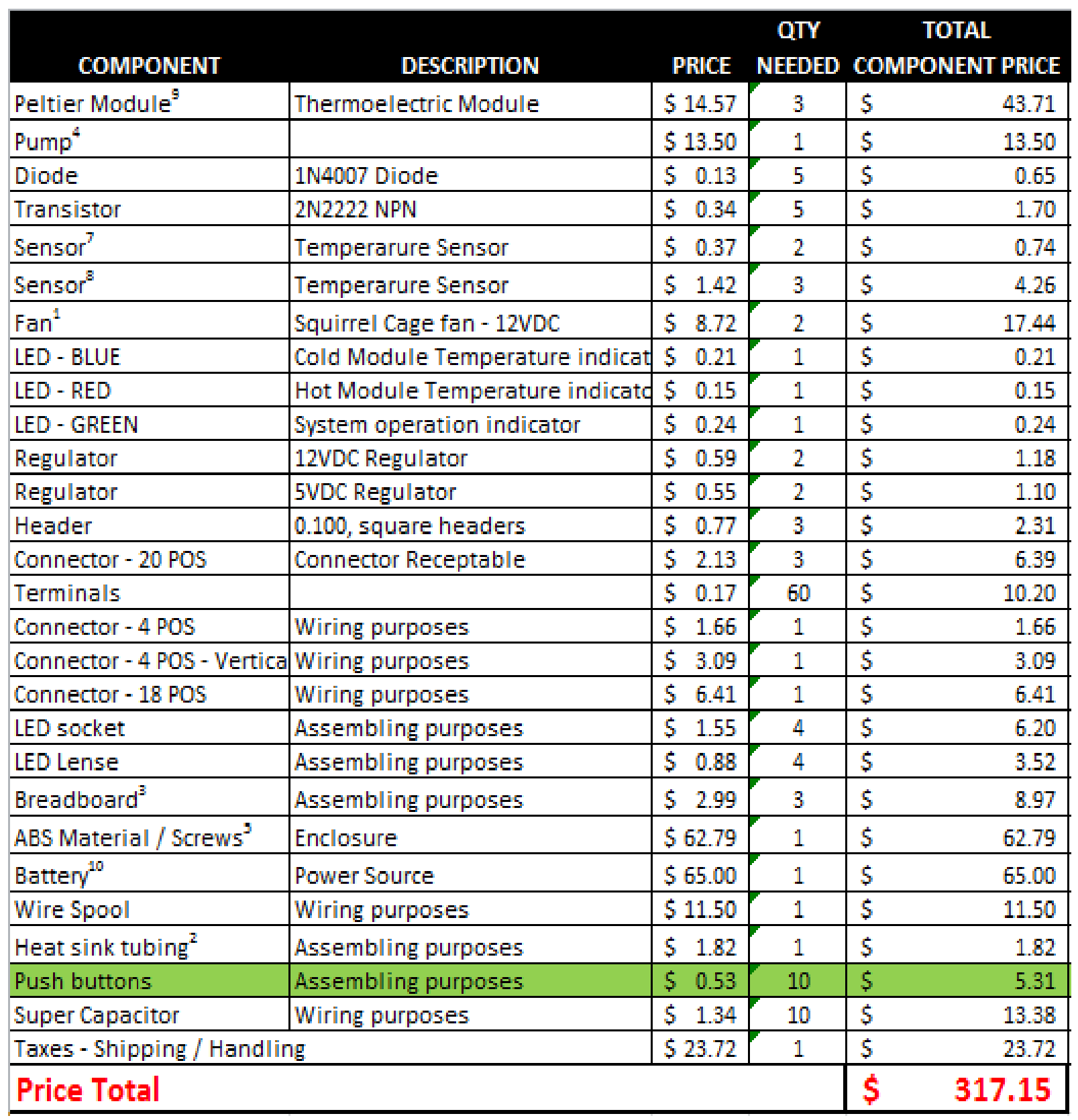




\section{Test Plan}

The test plan is illustrated in Table 3. Regular testing of software and hardware successful implementation of project prototype

Table 3: Testing Plan

\begin{tabular}{|c|c|}
\hline STAGE & PLAN \\
\hline Stage 1: Prototype & $\begin{array}{l}\text { - Research and purchase components that } \\
\text { meet power consumption criteria as well as } \\
\text { temperature operation range }\end{array}$ \\
\hline Stage 2: Hardware and Software interface & $\begin{array}{l}\text { - Program Arduino to control LCD to } \\
\text { display information } \\
\text { - Program Arduino to read thermistor and } \\
\text { display value on LCD } \\
\text { - Program Arduino to turn on specific } \\
\text { relays based on thermistor reading } \\
\text { - Program Trinket to control pump }\end{array}$ \\
\hline Stage 3: System updates & $\begin{array}{l}\text { - Latest design has } 5 \text { relays. One for each } \\
\text { individual element (Original design had } 3 \\
\text { relays). } \\
\text { - Latest design has ON/OFF switch for each } \\
\text { microcontroller as well as a reset button } \\
\text { - Latest design has two microcontrollers, } \\
\text { Arduino to control heating and cooling } \\
\text { element, and Trinket to control air freshener } \\
\text { pump }\end{array}$ \\
\hline Stage 4: System Test & $\begin{array}{l}\text { - Debug prototype } \\
\text { - Connect all component to prototype an } \\
\text { test unit as a whole } \\
\text { - Simulate temperature change by blowing } \\
\text { hot air to thermistor or placing an ice cube } \\
\text { next to thermistor } \\
\text { - Ensure that current power source is } \\
\text { adequate to sustain entire system }\end{array}$ \\
\hline Stage 5: Final Design Construction & $\begin{array}{l}\text { - Purchase additional hardware / project } \\
\text { boxes to enclose all components }\end{array}$ \\
\hline Stage 6: Final Design Test & $\begin{array}{l}\text { - Mount Final design into a compact car } \\
\text { and let run while monitoring temperature } \\
\text { and design functionality }\end{array}$ \\
\hline
\end{tabular}




\section{Problems Encountered}

There were some expected and some unexpected problems encountered throughout the development of prototype. Scheduling for meeting times outside of class was the greatest problem, since the group members had different schedules due to work or other school responsibilities.

Some of the technical problems are listed as follows:

- Installation of solar panel in the car

Problem: If the installation is in the back window panel, the window could deflect the sun light leaving the solar pane without any source of energy.

Solution: The solution is to look at what type of light or radiation the solar panel acquires the energy from; if most cars deflect the sun light, we need to get solar panel that gets energy from other type of light.

- Switching the Peltier modules (cooling to heating and vice versa)

Problem: The Peltier modules should change poles in order to cool or to heat up.

Solution: The Solution would be having an extra relay that is connected with switched poles, and with the microcontroller decide which relay is active.

- Microcontroller programing

Problem: Introduction to a new programming language is always a challenge, figuring out the logic and its syntax.

Solution: A solution would be to get a book about the microcontroller and get familiar with it so that the code can be more efficient.

- Power Consumption

Problem: The peltier modules will take the most energy out of the Lithium battery pack. Then test the prototype for power consumption to see the rate of consumption.

Solution:Find a solar panel that would provide the enough energy to charge at a higher rate than the consumption.

\section{Conclusion}

This paper described the design and successful implementation of a senior project "Heating and Cooling System for car's interior." The designed device can control the temperature of a car's interior when the car is not on or running its heater or AC. The device runs on energy generated from a solar panel mounted on the vehicle, making it self-sufficient and environmentally friendly. The application of the system is to maintain temperatures within a predetermined range 
inside the car for drivers to get inside a comfortable car. Moreover, the project allowed for an educational experience in which the team members incorporated concepts learned in their corresponding programs of EET and CET. The team members integrated concepts learned in electronic and programming courses to program a microcontroller and assemble the circuitry of the device.

\section{References}

1. "Categories." SparkFun Electronics. N.p., n.d. Web. 16 Aug. 2013.

2. "DigiKey Electronics - Electronic Components Distributor." DigiKey Electronics - Electronic Components Distributor. N.p., n.d. Web. 16 Aug. 2013.

3. "EBay." Electronics, Cars, Fashion, Collectibles, Coupons and More Online Shopping. N.p., n.d. Web. 16 Aug. 2013.

4. "Featured Products." California Sacramento CO2 Laser Engraving Cutting Machine \& Parts. Purchase or Rental. Electronics Supplier in Northern California for PID Temperature Controller, brushless Dc Water Pump, laser Controller, laser Power Supply. N.p., n.d. Web. 16 Aug. 2013.

5. "Home Improvement Made Easy with New Lower Prices | Improve \& Repair." Home Improvement Made Easy with New Lower Prices | Improve \& Repair. N.p., n.d. Web. 16 Aug. 2013.

6. "Jameco Electronics." - Electronic Components Distributor. N.p., n.d. Web. 16 Aug. 2013.

7. "MCM Electronics: Home and Pro Audio/Video, Security and Test Equipment." MCM Electronics: Home and Pro Audio/Video, Security and Test Equipment. N.p., n.d. Web. 16 Aug. 2013.

8. "McMaster-Carr." McMaster-Carr. N.p., n.d. Web. 16 Aug. 2013.

9. "Mouser Electronics - Electronic Components Distributor." Mouser Electronics - Electronic Components Distributor. N.p., n.d. Web. 16 Aug. 2013.

10. "Newark | US - Electronic Components Distributor|Electronic Parts Distributor." Newark| US - Electronic Components Distributor | Electronic Parts Distributor. N.p., n.d. Web. 16 Aug. 2013.

11. Wikipedia. Wikimedia Foundation, n.d. Web. 16 Aug. 2013. 